\title{
Electrochemotherapy increases local control after incomplete excision of a recurring penile fibrosarcoma in a stallion
}

\author{
E.P. Spugnini ${ }^{1, *}$, C. Bolaffio ${ }^{2}$, L. Scacco ${ }^{2}$ and A. Baldi ${ }^{1,3}$ \\ ${ }^{1}$ Biopulse S.r.l., Naples, Italy \\ ${ }^{2}$ Equivet Roma Hospital, Rome, Italy \\ ${ }^{3}$ Department of Environmental, Biological and Pharmaceutical Sciences and Technologies, Second University of \\ Naples, Italy
}

\begin{abstract}
An eleven-year-old stallion was referred for adjuvant treatment of an incompletely excised, recurring penile fibrosarcoma. The horse was bright, alert and responsive with a $15 \times 12 \mathrm{~cm}$ ulcerated lesion on the ventral side of the penis. The lesion was the tumor bed of an incompletely excised fibrosarcoma. After complete staging procedures, the owner elected to treat the horse with electrochemotherapy (ECT) using cisplatin as chemotherapy agent. Two sessions of ECT were performed at two-week intervals using local cisplatin followed by trains of biphasic electric pulses applied using different electrodes until complete coverage of the area was achieved. The treatment was well tolerated, and the patient is still disease free after 12 months. ECT resulted in improved local control and should be considered among the available adjuvant treatments in equines carrying soft tissue tumors.
\end{abstract}

Keywords: Cisplatin, Electrochemotherapy, Equine, Fibrosarcoma.

\section{Introduction}

The skin is the most common tumor location in equines as shown by the current veterinary literature, and the most frequently reported neoplasms are sarcoids, melanoma and squamous cell carcinoma (Knottembelt et al., 2015). On the other hand, tumors originating from malignantly transformed fibroblasts, such as fibrosarcoma, are exceedingly rare (Knottembelt et al., 2015). The prognosis for this uncommon tumor is good provided that it is diagnosed early and surgically excised with wide margins. Otherwise, the malignancy can recur and become extremely aggressive (Knottembelt et al., 2015). Moreover, the excision of these tumors can be challenging should they be localized in surgically difficult districts such as the head or the genitals (especially the males') (Van Den Top et al., 2008a; Rizk et al., 2013).

In the case of recurrence or large tumor extension, chances of local control can be increased by combining cryotherapy or teletherapy, the latter being not widely available to equines (Knottembelt et al., 2015). In this article, we report the successful outcome of a recurring penile fibrosarcoma that was treated with surgery and electrochemotherapy (ECT).

\section{Case details}

An eleven-year-old stallion was referred for evaluation of an incompletely excised recurring penile fibrosarcoma (Fig. 1A). The lesion had been excised two months earlier and upon recurrence, a conservative surgery had been performed upon owner's request and submitted for histopathological evaluation. The histopathology report came back with a diagnosis of incompletely excised fibrosarcoma, characterized by a fasciculated growth pattern of spindle-shaped cells with scant cytoplasm and indistinct borders and invasive growth; high mitotic activity was present with abnormal forms (Fig. 1E).

At this point, the horse was referred for oncology consult to discuss therapeutic options. At presentation, the horse was bright, alert, responsive, and presented a large poorly healing ulcerated lesion on the ventral side of the penis measuring $15 \times 12 \mathrm{~cm}$ (Fig. 1A).

The horse was staged with a complete blood cell count, biochemistry profile, and urinalysis. Moreover, an abdominal ultrasonographic exam was performed, and thoracic radiographs were taken. All the hematobiochemical parameters were within normal limits except for a moderate neutrophilia (87\%), probably secondary to the ulceration.

The imaging exams did not show metastatic spread or other underlying disorders. At this point, the options to increase the chances of local control included: surgical revision, potentially including partial phallectomy or amputation (Doles et al., 2001; Van Den Top et al., 2008a, 2008b, 2010; Rizk et al., 2013), intralesional chemotherapy (Théon et al., 1994, 1999) or ECT (Spugnini and Baldi, 2014; Spugnini et al., 2014). The owner elected the patient to be treated with ECT to maximize the chances of local control while preserving organ function. 

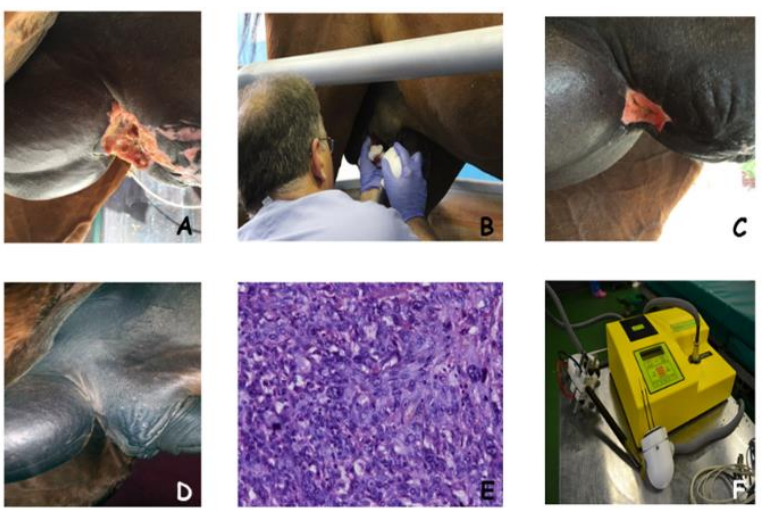

Fig. 1. (A): The tumor lesion at presentation. A $15 \times 12 \mathrm{~cm}$ ulcer on the ventral aspect of the horse penis. (B): Intratumoral delivery of permeabilizing electric pulses by means of a needle array electrode. (C): The lesion after one session of ECT. (D): The patient at 1 month recheck after completion of ECT: there is no gross evidence of cancer disease in the previously treated tumor site. (E): Histological appearance of the neoplasia: a highly cellular fibroblastic proliferation in herringbone pattern constituted by cells with scant cytoplasm, tapering elongated dark nuclei with increased granular chromatin and variable nucleoli (Hematoxylin and Eosin staining; original magnification X20). (F): The electroporation equipment with plate electrode (left side of the image) and needle array electrode (close up of the image).

The horse was sedated with a combination of acepromazine (Prequillan, Fatro, Ozzano Emilia, Italy), butorphanol (Nargesic, ACME, Cavriago, Italy) and detomidine (Domidine, Dechra, Milan, Italy) at the doses of $0.03 \mathrm{mg} / \mathrm{kg}, 0.04 \mathrm{mg} / \mathrm{kg}$ and $0,005 \mathrm{mg} / \mathrm{kg}$ respectively, additionally, local anesthesia was performed by perilesional injection of $2 \%$ lidocaine (Lidocaina 2\%, Zoetis, Rome, Italy) (Schumacher, 2006).

The neoplastic ulcer and $1 \mathrm{~cm}$ of normal tissue were injected with cisplatin (Cisplatino Teva Italia, Milan, Italy) at the concentration of $1 \mathrm{mg} / \mathrm{ml}$ until saturation was reached (total volume $15 \mathrm{ml}$ ). Five minutes after the injection, trains of 8 biphasic pulses at the voltage of $800 \mathrm{~V} / \mathrm{cm}, 1 \mathrm{~Hz}$ frequency, lasting $50+50 \mu$ s with $300 \mu \mathrm{s}$ interpulse (total treatment time per $\mathrm{cm} 3.2 \mathrm{~ms}$ ) were administered by means of a clinical electroporator certified for veterinary application (Onkodisruptor®, Biopulse S.r.l., Naples, Italy) using needle array and plates electrodes until complete coverage of the lesion was achieved (Fig. 1B, F).

The patient did not show any side effects due to the therapy and was discharged under antibiotics and nonsteroidal anti-inflammatory drugs: trimethoprimsulfamethoxazole (Naxoprim, ACME S.r.l., Cavriago, Italy) $30 \mathrm{mg} / \mathrm{kg}$ OS SID and phenylbutazone (Bute ACME S.r.l., Cavriago, Italy) 2,2 mg/kg IV SID. After two weeks the patient came back for a recheck appointment showing a clear reduction of the tumoral ulcer (Fig. 1C). At this time, a second ECT procedure was performed. The lesion continued its healing and after one month from the second ECT went into complete remission (Fig. 1D).

The patient has been monthly rechecked with a physical exam for three months and then has been monitored on a three months schedule. At these times, thoracic radiographs were taken, and an abdominal ultrasonographic exam was performed to check for possible metastatic spread. After one year the patient is still disease free with a preserved organ function.

\section{Discussion}

Penile and preputial tumors are rare in horses and represent diagnostic and therapeutic challenges. When conservative surgical resection is deemed unfeasible, the options include partial phallectomy and penile amputation (Schumacher and Vaughan, 1988; Howarth et al., 1991; Mair et al., 2000; Arnold et al., 2010; Van Den Top et al., 2011).

Regarding the histotypes occurring in this body district, squamous cell carcinoma and melanoma are the most commonly diagnosed (Johnson, 1998; Valentine, 2006; Van Den Top et al., 2008a, 2010; Arnold et al., 2010). Neoplasia of the male genitalia has been more frequently reported in equine than in other domestic animals; they account from 6 to $10 \%$ of all neoplasms in equine (Van Den Top et al., 2008a, 2008b, 2010; Rizk et al., 2013).

On the other hand, fibrosarcoma, a malignant tumor derived from fibrous connective tissue and characterized by immature proliferating fibroblasts or undifferentiated anaplastic spindle cells, has been infrequently reported in horses (Van Den Top et al., 2008a, 2008b, 2010; Rizk et al., 2013). Large tumors of this district, such as the one described in this case report, can interfere with coitus or normal protrusion and retraction of the penis (Rizk et al., 2013).

According to current literature, recurrence after surgical excision has been reported in $17-25 \%$ of advanced tumor cases, besides, these tumors may spread to regional lymph nodes if not aggressively treated (Van Den Top et al., 2008a, 2008b, 2010; Rizk et al., 2013). Adjuvant intralesional or intraoperative chemotherapy can improve local control but might result in local side effects, including inflammation (Théon et al., 1994, 1999).

To date, partial phallectomy is considered an effective therapy only for tumors confined to the glans and body of the penis in absence of local and distant dissemination (Rizk et al., 2013). ECT is a locoregional therapy that is gaining popularity among the veterinary community for its ability to increase local tumor control with minimal side effects. This technique involves the application of permeabilizing electric pulses on tumors or tumors' beds after the administration (either systemic or intralesional) of a 
chemotherapy agent such as bleomycin or cisplatin (Spugnini and Baldi, 2014). This technique has been successfully employed to increase the chemotherapy efficacy in dogs and cats affected by soft tissue sarcoma (Spugnini et al., 2007, 2008a, 2011a).

Moreover, our group has been able to successfully treat tumors in the genital district of male dogs in a small preliminary investigation (Spugnini et al., 2008b). In this case, the owner elected to treat with ECT his horse, aiming at improving the chances to achieve local control also in consideration of its reported efficacy in other malignant equine neoplasms (Spugnini et al., 2011b, Scacco et al., 2013).

ECT was well tolerated, and after one year from the completion of the therapy, the horse has still no evidence of disease. To the best of our knowledge, this is the first report of penile fibrosarcoma in horses treated with this modality. Our group is currently using ECT as standard adjuvant therapy for incompletely excised solid tumors in horses with good results and tolerability. Further investigations are warranted to confirm this preliminary finding and to evaluate the usefulness of ECT in equine oncology.

\section{Conflict of interest}

Enrico P. Spugnini and Alfonso Baldi are stockoholders of Biopulse S.r.l.

\section{References}

Arnold, C.E., Brinsko, S.P., Love, C.C. and Varner, D.D. 2010. Use of a modified Vinsot technique for partial phallectomy in 11 standing horses. J. Am. Vet. Med. Assoc. 237, 82-86.

Doles, J., Williams, J.W. and Yarbrough, T.B. 2001. Penile amputation and sheath ablation in the horse. Vet. Surg. 30, 327-331.

Howarth, S., Lucke, V.M. and Pearson, H. 1991. Squamous cell carcinoma of the equine external genitalia: a review and assessment of penile amputation and urethrostomy as a surgical treatment. Equine Vet. J. 23, 53-58.

Johnson, P.J. 1998, Dermatologic tumors (excluding sarcoids). Vet. Clin. North Am. Equine Parct. 14, 625-658.

Knottembelt, D.C., Patterson-Kane, J.C. and Snalune, L.L. 2015. Tumors of the skin. In: Clinical equine oncology, Eds., Knottembelt, D.C., Patterson-Kane. J.C., and Snalune. L.L., Philadelphia PA, Elsevier publisher, pp: 544-584.

Mair, T.S., Walmsley, J.P. and Phillips, T.J. 2000. Surgical treatment of 45 horses affected by squamous cell carcinoma of the penis and prepuce. Equine Vet. J. 32, 406-410.

Rizk, A., Mosbah, E., Karrouf, G. and Abou Alsoud, M. 2013. Surgical management of penile and preputial neoplasms in equine with special reference to partial phallectomy. J. Vet. Med. http://dx.doi.org/10.1155/2013/891413.

Scacco, L., Bolaffio, C., Romano, A., Fanciulli, M., Baldi, A. and Spugnini, E.P. 2013. Adjuvant electrochemotherapy increases local control in a recurring equine anal melanoma. J. Equine Vet. Sci. 33, 637-639.

Schumacher, J. and Vaughan, J.T. 1988. Surgery of the penis and prepuce. Vet. Clin. North Am. Equine Pract. 4, 473-491.

Schumacher, J. 2006. Anaesthesia of the head and penis. In: Doherty, T., Valverde, A., editors. Manual of Equine Anaesthesia and Analgesia. Oxford, UK: Blackwell, pp: 886-911.

Spugnini, E.P., Vincenzi, B., Citro, G., Santini, D., Dotsinsky, I., Mudrov, N., Montesarchio, V., Laieta, M.T., Esposito, V. and Baldi, A. 2007. Adjuvant electrochemotherapy for the treatment of incompletely excised spontaneous canine sarcomas. In Vivo 21, 819-822.

Spugnini, E.P., Citro, G., D'Avino, A. and Baldi, A. 2008a. Potential role of electrochemotherapy for the treatment of soft tissue sarcoma: first insights from preclinical studies in animals. Int. J. Biochem. Cell Biol. 40, 159-163.

Spugnini, E.P., Dotsinsky, I., Mudrov, N., Cardosi, G., Citro, G., D'Avino, A. and Baldi, A. 2008b. Biphasic pulses enhance bleomycin efficacy in a spontaneous canine genital tumor model of chemoresistance: Sticker sarcoma. J. Exp. Clin. Cancer Res. 27, 58.

Spugnini, E.P., Renaud, S.M., Buglioni, S., Carocci, F., Dragonetti, E., Murace, R., Cardelli, P., Vincenzi, B., Baldi, A. and Citro, G. 2011a. Electrochemotherapy with cisplatin enhances local control after surgical ablation of fibrosarcoma in cats: an approach to improve the therapeutic index of highly toxic chemotherapy drugs. J. Transl. Med. 9, 152.

Spugnini, E.P., D’Alterio, G.L., Dotsinsky, I., Mudrov, T., Dragonetti, E., Murace, G., Citro, G. and Baldi, A. 2011b. Electrochemotherapy for the treatment of multiple melanomas in a horse. J. Equine Vet. Sci. 31, 430-433.

Spugnini, E.P. and Baldi, A. 2014. Electrochemotherapy in veterinary oncology: from rescue to first line therapy. Methods Mol. Biol. 1121, 247-256.

Spugnini, E.P., Melillo, A., Quagliuolo, L., Boccellino, M., Vincenzi, B., Pasquali, P. and Baldi, A. 2014. Definition of novel electrochemotherapy parameters and validation of their in vitro and in vivo effectiveness. J. Cell Physiol. 229, 1177-1181.

Théon, A.P., Pascoe, J.R. and Meagher, D.M. 1994. Perioperative intratumoral administration of 
cisplatin for treatment of cutaneous tumors in equidae. J. Am. Vet. Med. Assoc. 205, 1170-1176.

Théon, A.P., Pascoe, J.R., Galuppo, L.D., Fisher, P.E., Griffey, S.M. and Madigan, J.E. 1999. Comparison of perioperative versus postoperative intratumoral administration of cisplatin for treatment of cutaneous sarcoids and squamous cell carcinomas in horses. J. Am. Vet. Med. Assoc. 215, 1655-1660.

Valentine, B.A. 2006. Survey of equine cutaneous neoplasia in the Pacific Northwest. J. Vet. Diagn. Invest. 18, 123-126.

Van Den Top, J.G., De Heer, N., Klein, W.R., Klein, W.R. and Ensink, J.M. 2008a. Penile and preputial tumours in the horse: a retrospective study of 114 affected horses. Equine Vet. J. 40, 528-532.
Van Den Top, J.G., De Heer, N., Klein, W.R. and Ensink, J.M. 2008b. Penile and preputial squamous cell carcinoma in the horse: a retrospective study of treatment of 77 affected horses. Equine Vet. J. 40, 533-537.

Van Den Top, J.G., Ensink, J.M., Gröne, A., Klein, W.R., Barneveld, A. and Van Weeren, P.R. 2010. Penile and preputial tumours in the horse: literature review and proposal of a standardised approach. Equine Vet. J. 42, 746-757.

Van Den Top, J.G., Ensink, J.M., Barneveld, A. and van Weeren, P.R. 2011. Penile and preputial squamous cell carcinoma in the horse and proposal of a classification system. Equine Vet. Ed. 23, 636648. 